\title{
Quantifying likely cetacean range shifts in response to global climatic change: implications for conservation strategies in a changing world
}

\author{
Emily Lambert ${ }^{1, *}$, Colin D. MacLeod ${ }^{1}$, Karen Hall ${ }^{1}$, Tom Brereton ${ }^{2}$, \\ Timothy E. Dunn ${ }^{3}$, Dave Wall ${ }^{4}$, Paul D. Jepson ${ }^{5}$, Rob Deaville ${ }^{5}$, Graham J. Pierce ${ }^{1,6}$ \\ ${ }^{1}$ Institute of Biological and Environmental Sciences (IBES), University of Aberdeen, Tillydrone Avenue, Aberdeen AB24 2TZ, UK \\ ${ }^{2}$ Marinelife, 12 St Andrews Road, Bridport, Dorset DT6 3BG, UK \\ ${ }^{3}$ Joint Nature Conservation Committee, Inverdee House, Baxter Street, Aberdeen AB11 9QA, UK \\ ${ }^{4}$ Irish Whale and Dolphin Group, Merchants Quay, Kilrush, Co. Clare, Ireland \\ ${ }^{5}$ Institute of Zoology, Regents Park, London NW1 4RY, UK \\ ${ }^{6}$ Instituto Español de Oceanografía, Centro Oceanográfico de Vigo, PO Box 1552, 36200 Vigo, Spain
}

\begin{abstract}
As with many other taxa, climate change is expected to result in geographic range shifts of cetacean species as they track changes in temperature to remain within their ecological niches. Such changes in geographic range could have implications for the conservation and management of cetaceans. Here, we propose a bioclimatic envelope modelling approach for providing quantitative predictions of how the ranges of cetacean species may respond to changing water temperatures. This combines predictions from habitat niche and 'thermal' niche models for an individual species to determine probable geographic range under specific climatic conditions. However, if this approach is to be used to inform conservation strategies, it is essential that the ability to predict responses to environmental change is validated beyond the period of data collection used to construct the models. Therefore, in addition to validation of modelled current range, we included a step to validate the models' ability to predict previous changes in range over time in response to climatic changes using independent data. We demonstrate this approach using common dolphin Delphinus delphis data from the Northeast Atlantic. The combined model was constructed with data collected between 1980 and 2007, and validated using independent distributional records collected between 1930 and 2006. The validated model was then applied to predict future range between 2010 and 2069, based on projected water temperatures. Thus, the modelling approach is shown to provide the type of information required to help ensure that conservation and management strategies remain effective in the face of a changing climate.
\end{abstract}

KEY WORDS: Global climate change $\cdot$ Cetaceans $\cdot$ Range changes $\cdot$ Conservation $\cdot$ Ecological niche model $\cdot$ Water temperature

\section{INTRODUCTION}

A species' geographic range is determined by the spatio-temporal distribution of environmental variables that define its occupied niche: that is, the areas of the fundamental niche where a species actually occurs (Hutchinson 1957, Kearney 2006). There is increasing evidence that the geographic ranges of a wide variety of taxa are shifting in response to climate change as they track, amongst other factors, the changing spatio-temporal distribution of temperatures that define their thermal niche (e.g. Walther et 
al. 2002, Parmesan \& Yohe 2003, Thomas 2010). Bioclimatic envelope models (also known as 'ecological niche models' or 'species distribution models') suggest that such range shifts are likely to continue with further changes in climate (Thomas et al. 2004, Levinsky et al. 2007).

Following this rationale, the ranges of cetacean species are expected to shift in response to changes in climate (Learmonth et al. 2006). MacLeod (2009) provided a qualitative framework for understanding the likely direction of cetacean range changes, which suggests that the majority of marine cetacean species ranges will be affected by changing temperatures, and that these effects are likely to have negative conservation implications for almost half of these species. If these range shifts occur in the short to medium term, some traditional conservation and management strategies, such as the establishment of static reserves, may no longer remain viable. In particular, over time, this could lead to a mismatch between the spatial distribution of species and areas targeted by management (Pyke et al. 2005, Robinson et al. 2009). In addition, many other conservation and management strategies require a reasonable understanding of species distribution for successful implementation (e.g. DEFRA 2009). As a result, understanding how species spatial distributions, and particularly ranges, are likely to alter in response to climate change presents an important challenge for cetacean conservation and management. Specifically, for any conservation strategy to remain effective and adaptive, it is increasingly critical to be able to account for the potential response of species to changes in temperature (Peters \& Darling 1985, Hannah et al. 2002, Svenning et al. 2009).

However, while the qualitative effects of temperature changes on cetacean species ranges are relatively well understood (e.g. Learmonth et al. 2006, Simmonds \& Isaac 2007, MacLeod 2009), there is currently no framework for providing quantitative predictions of how species ranges may respond to climate change, despite evidence of climate-related cetacean range shifts already apparent in some regions (e.g. MacLeod et al. 2005, Leeney et al. 2008, Salvadeo et al. 2010). Thus, here we provide a simple bioclimatic envelope modelling approach that combines elements of cetacean habitat niche modelling with a quantification of thermal niche of cetaceans. Specifically, this develops and quantifies the qualitative framework for investigating how cetacean species ranges will respond to changes in climate proposed by MacLeod (2009), which grouped species according to their likely response to water temperature changes. As both the framework developed by MacLeod (2009) and that considered here are empirical, a mechanical understanding of the relationship between water temperature and cetacean range is not required (i.e. it is not imperative to understand why cetacean distributions are related to temperature, only to empirically demonstrate that they are).

The proposed approach consists of 3 stages (Fig. 1). Firstly, the relationship between species spatial distribution and habitat variables is modelled to control for the effects of topographic discontinuities on species occurrence and the ability of a species to track its preferred thermal niche (Fig. 1, Boxes 1-4). MacLeod (2009) highlighted this as an essential issue to consider when investigating how cetacean ranges will respond to change in climate. Next, the thermal niche occupied by the species is modelled based on one of the 4 climate change response groupings proposed by MacLeod (2009) (Fig. 1, Boxes 2 \& 5-8): warm water limited species (WWL, see Fig. 2), cool and warm water limited species (CWWL), cool water limited species (CWL), and cosmopolitan species. Species in each of these groupings are expected to respond, in terms of their range, in a similar manner, with each grouping associated with a function of a specific form (see Appendix 1 for details). When quantified for a particular species, this function forms a model of the thermal niche occupied by a species, and hence, its range in relation to spatial patterns in water temperature. This thermal niche model is then used to weight the habitat niche model for a timespecific water temperature data set to produce a predicted species range for a specific period of time, which accounts for both topographic preferences and water temperature preferences (Fig. 1, Boxes 4 \& 8-11).

The thermal niche and habitat niche models are conducted as separate steps in this process as preferences for individual habitat variables are likely to differ depending on where temperatures at specific locations fall in relation to the species thermal niche (Fig. 2). When water temperatures lie outside the species thermal niche, the species will not occur even within the most favoured habitat combinations. In contrast, within the thermal niche, temperature is unlikely to influence the species distribution, which instead will be primarily influenced by habitat preferences. At the edges of the thermal niche, an interaction between water temperature and habitat preferences is likely, meaning that as temperatures become less favourable, the species becomes more and more restricted to the most preferred habitat 


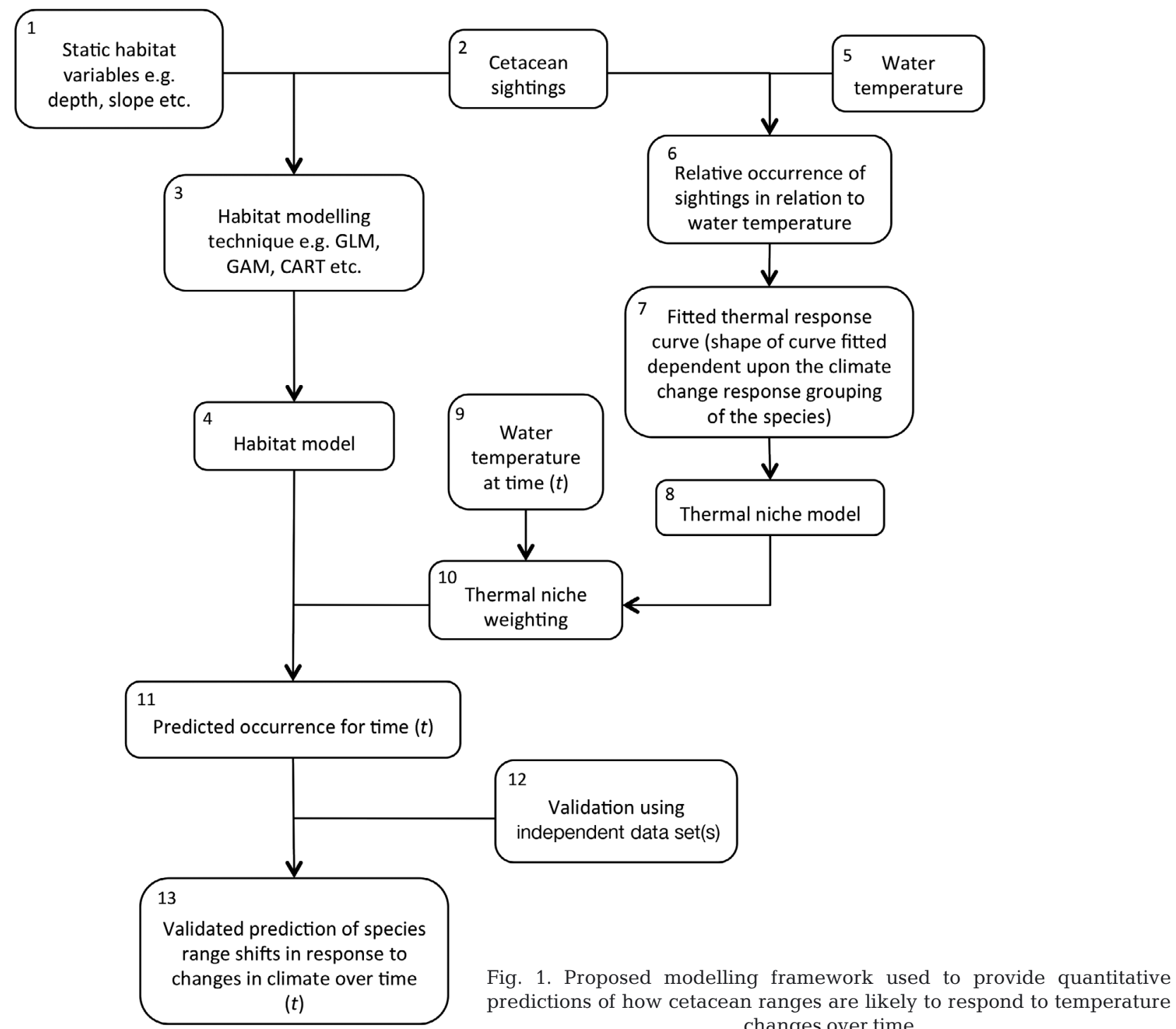
predictions of how cetacean ranges are likely to respond to temperature changes over time

combinations. Consequently, by dividing the niche characteristics into those that will change with climate (temperature) and those which are essentially fixed (habitat), the modelling process becomes simpler to understand and conduct, and therefore more widely applicable. However, despite this simplicity, it can still account for the complex interaction between the temperature niche and the habitat niche occupied by a species.

The final stage of the modelling process consists of 2 validation steps. The first evaluates the ability of the model to predict the current static spatial distribution of the species using data collected during the same time period as that used to build the model. This ensures that the model accurately captures both the habitat niche and its interaction with the thermal niche for a single period in time, and therefore represents a good model of the species current range. The second step validates the ability of the model to predict changes in species range over time in response to previous changes in climate using an independent dataset that covers a longer time period than that of the data used to construct the model (Fig. 1, Boxes 11-13). This second validation step specifically assesses the ability of the model to make predictions across a period of environmental change and beyond the period of data collection, rather than simply reflect the 'static' distribution of a species, which is essential if this approach is to be applied to understanding how cetacean ranges are likely to change in 


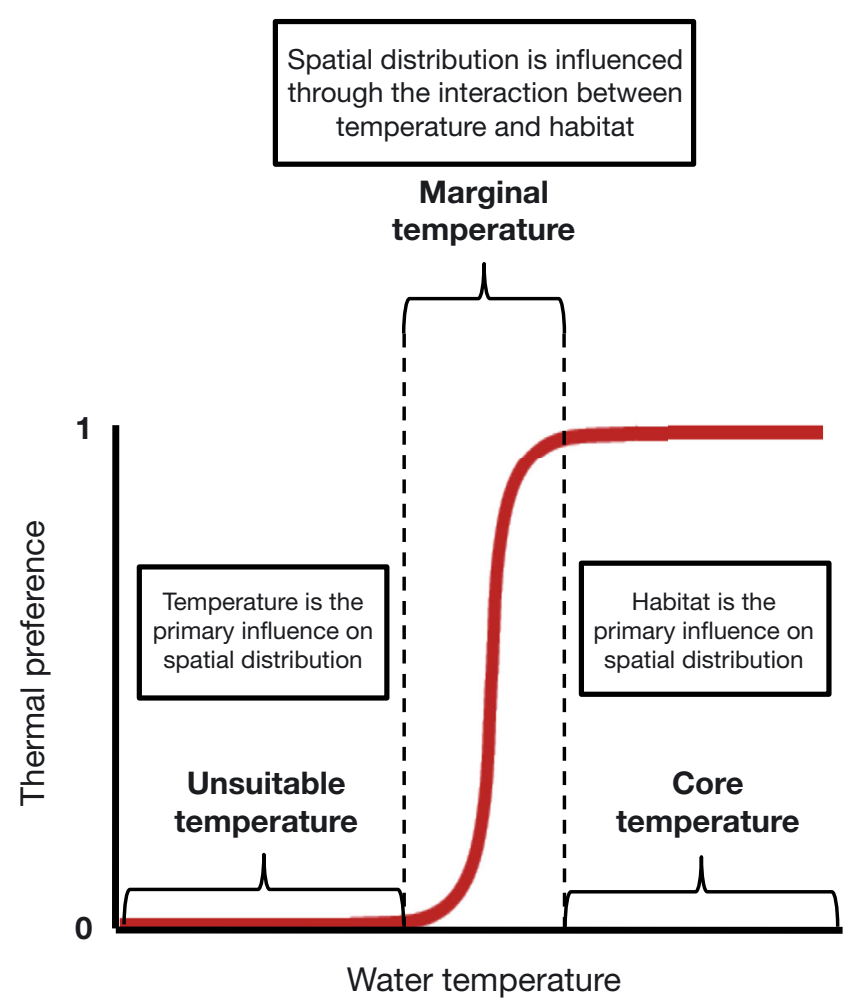

Fig. 2. Thermal niche function for warm water limited species. Species occurrence increases with increasing water temperature from a starting asymptote of 0 (outside of the thermal niche), until an asymptote is reached at a value of 1 (firmly within the thermal niche). The interaction between habitat and temperature preferences alters depending on the location of a species in relation to its thermal niche. As such, a species may occupy a much wider range of habitats when close to the core of its thermal niche than when close to the edge of it, and will not occur in even the most preferred habitats when the water temperatures lie outside its thermal niche

response to climate change for conservation and management purposes.

We demonstrate this approach by using it to investigate how the range of common dolphin Delphinus delphis in the Northeast Atlantic is likely to change in response to future changes in temperature. The area and species were chosen due to the availability of data to construct and validate the models, and because this represents the region where common dolphins are at the cool water limit of their current range (Weir et al. 2001, MacLeod et al. 2007). As a consequence, common dolphin range changes associated with changes in climate are most likely to be detected in region (MacLeod 2009). Indeed, evidence consistent with temperature-induced range changes in common dolphin has already been identified in this area (MacLeod et al. 2005).

\section{MATERIALS AND METHODS}

\section{Study area and model construction data}

The study area covered the Northeast Atlantic from northern Spain in the south to Norway and Iceland in the north (Fig. 3). To construct the required habitat niche and thermal niche models, sightings data were obtained from long-term data sets collected between 1980 and 2007 by the Joint Nature Conservation Committee (JNCC), the Irish Whale and Dolphin Group (IWDG) and Marinelife. Where species identification was unclear, sightings were assigned to the lowest level of taxonomic certainty. Only summer sightings (June to September) were analysed due to limited data availability for other seasons and to avoid the complication of incorporating seasonal shifts in distribution, such as offshore/onshore movements. In addition, the thermal preference of common dolphin in this region is much better understood in summer months than in winter months (e.g. MacLeod et al. 2007). All sightings were entered into a GIS created using ESRI Arcview 9.2.

\section{Habitat niche model}

The habitat niche model was quantified based on 3 variables: water depth, seabed slope and standard deviation of seabed slope. These variables were selected, as they are known to be the most important variables for determining the topographic habitat preferences of cetaceans in this region (Kiszka et al. 2007, MacLeod et al. 2007, Weir et al. 2009) and so are likely to present the greatest constraints on species occurrence within their thermal niche. Data on water depth were obtained from the combination of 2 data sets: DigiBath 250 (British Geological Society), used only for the coastal waters of western Scotland due to its complex coastline and seabed topography; and ETOP02, used for the remainder of the study area. Each depth data set was converted to a $2.5 \mathrm{~km}^{2}$ depth grid for the appropriate area. Grids for seabed slope and standard deviation of slope were derived from these 2 depth data sets. The resulting DigiBath and ETOP02 grids were then merged together to form 3 continuous $2.5 \mathrm{~km}^{2}$ grids of depth, slope and standard deviation of slope covering the whole study area. Data for these 3 variables were extracted and linked to each sighting.

Of the wide range of techniques available to model a species' habitat niche (see Redfern et al. 2006 for a review of possible approaches), we selected classifi- 

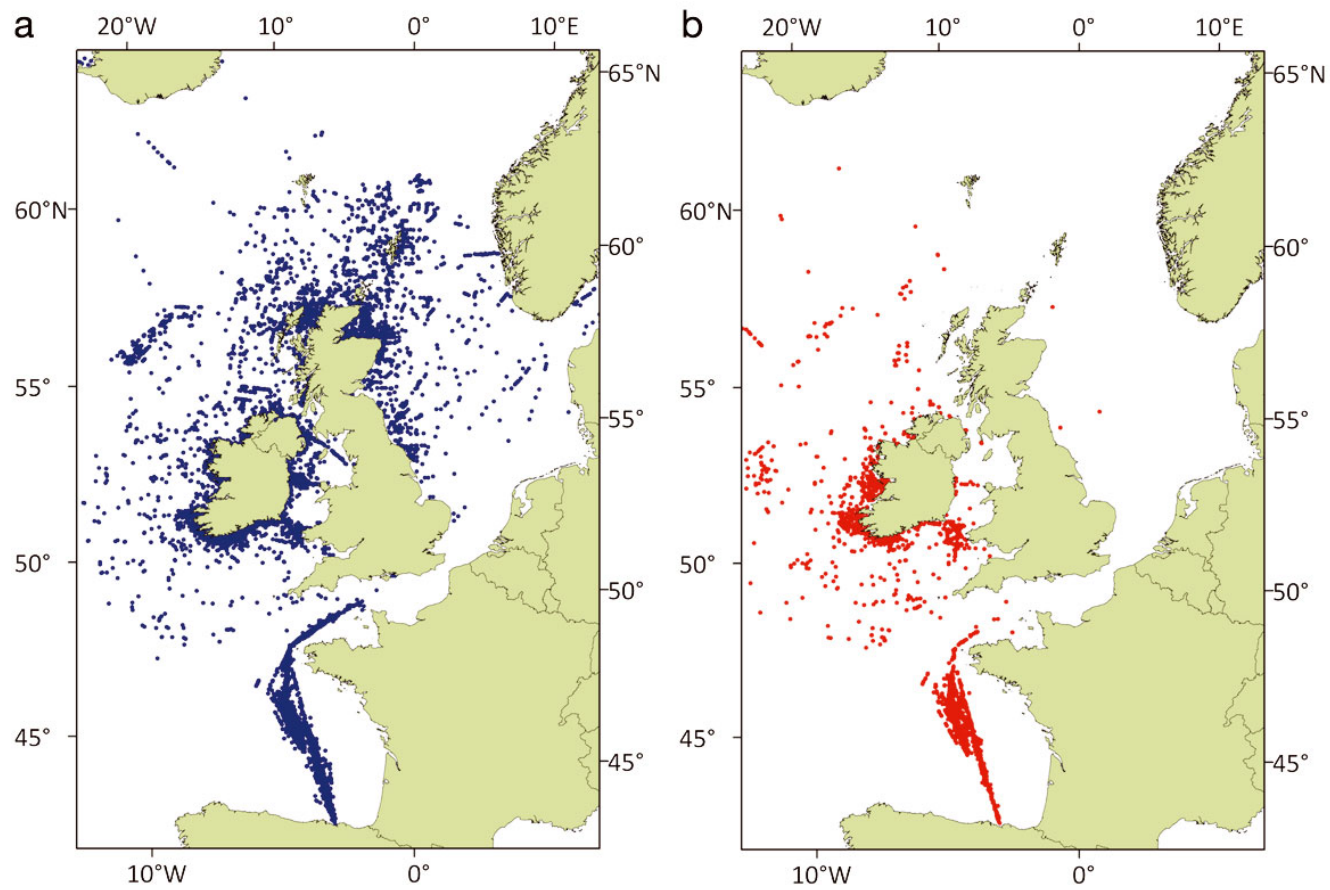

Fig. 3. Distribution of sightings data used to produce the common dolphin Delphinus delphis habitat niche model. (a) Sightings of other cetacean species, used as absence data points. (b) Common dolphin sightings, used as presence data points

cation trees to model the common dolphin habitat niche. Classification trees provide a relatively simple and easily interpretable model that is understandable to non-specialists. This is an important consideration when results might need to be understood by stakeholders and end-users who are not necessarily familiar with complex habitat modelling techniques.

Following MacLeod et al. (2007), when producing the classification tree, sightings data for common dolphin $(n=2718)$ were used as presence points (i.e. they represent habitat combinations that common dolphins are known to utilise), and sightings of other species $(n=13082)$ were used as absence points, as they indicate surveyed combinations of habitat variables that were sampled during survey effort, but where common dolphins were not recorded. While the use of the sighting locations of other species as absence data points may not reflect all locations where common dolphins were not recorded, they provide a measure of the combinations of habitats where it occurs in comparison to the general cetacean 'niche' occupied in the Northeast Atlantic (see MacLeod et al. 2007 for further consideration of this issue). However, using the locations of other species as absence data points for common dolphin could, theoretically, mean that actual habitat preferences may be misspecified if these locations are not representative of all available habitat combinations for the variables included in the model. This is most likely to occur with relatively small data sets rather than the sample of $\sim 16000$ locations used in this study, which means almost all available combinations of the 3 variables in the study area are likely to have been sampled. However, whether this limitation causes a major bias for the final species range model is directly assessed in the first validation step below, where the ability of the resulting model to accurately predict the current spatial distribution is assessed.

The initial classification tree was pruned using cross-validation to select a tree size with the smallest estimated error (see De'ath \& Fabricius 2000). This ensured a reasonably simple tree that incorporated only the most important relationships between species distributions and the variables included in the model, and which are those most likely to limit a species distribution within the thermal niche. The classification tree analysis was conducted using BRODGAR software (Highland Statistics) linked to R 2.6.0 (R Development Core Team).

The resulting classification tree model of the habitat niche was then applied to the study area as a whole. This was achieved by assigning a probability of occurrence, derived from the proportion of presence cells out of the total number of cells at the terminal nodes of the tree, to each grid cell based on the 
values assigned to the topographic variables therein. This produced a modelled distribution based on the habitat niche occupied by common dolphin in the Northeast Atlantic in terms of the 3 variables included in the model.

\section{Thermal niche model}

Gridded monthly sea surface temperature (SST) data from 1980 to 2007 were obtained from the Met Office HadiSST dataset at a $1^{\circ}$ resolution. The appropriate SST data were extracted for all sightings within the data set based on the location of the sighting and the month and year in which it was recorded. Next, sightings data were divided into $1^{\circ} \mathrm{C}$ temperature categories, and the proportion of common dolphin sightings in relation to sightings of all species in each category was calculated. This provided a probability distribution of common dolphin occurrence in relation to water temperature. The probability distribution of common dolphin in each $1^{\circ} \mathrm{C}$ temperature class was then re-classified into 3 categories of water temperatures: where the species does not usually occur and is therefore outside its thermal niche (value: 0); where the species occurs but is not common (0.5); and where the species commonly occurs (1). These 3 categories equate to the unsuitable, marginal and core sections of the thermal niche respectively (Fig. 2) and allow a single sigmoidal function to be easily fitted to represent the differing relationship between species occurrence and water temperature in these sections of the thermal niche. Where the proportional occurrence of common dolphin within a temperature category was $>25 \%$ of its maximum proportional occurrence in any temperature category, it was re-classified as common and assigned a value of 1 . When this proportional occurrence was between 5 and $25 \%$, it was re-classified as uncommon and given a value of 0.5 . When the occurrence was $<5 \%$, it was re-classified as rare/absent and given a value of 0 .

In order to ensure sufficient data were available for us to be confident that the occurrence of a species within a particular $1^{\circ} \mathrm{C}$ temperature class is likely to be an accurate representation of the species distribution in relation to water temperature, the species rarity needs to be accounted for. This was achieved by calculating the proportion of all sightings that were common dolphin and using this as the minimum number of cetacean records required to assign a high probability that the species would be recorded if present in a particular temperature class. In the case of common dolphin, 1 in 6 of all sightings in the whole dataset belonged to this species. Therefore, only those temperature categories containing $\geq 6$ sightings were used to calculate the thermal niche model for this species.

Next, the common dolphin was assigned to one of the 4 possible climate-change response groupings proposed by MacLeod (2009) based on its known distribution in relation to water temperatures within the study area (as determined from current literature). The sigmoidal thermal niche function can then be estimated by fitting a specific equation (relevant to the appropriate climate-change response grouping) to the re-classified probability distribution of occurrence in relation to water temperature using an iterative process to find the best fit. As common dolphins within the study area are likely to be WWL (Rice 1998, Kaschner 2004, MacLeod 2009), the following function was used to define the thermal niche:

$$
T N=0+\frac{1}{1+10^{(c-T) s}}
$$

The values for this function in relation to common dolphin were derived by randomly assigning values between the minimum and maximum possible values for slope ( $s$ : between 0 and 1 ) and central point $\left(c\right.$ : between -2 and $50^{\circ} \mathrm{C}$ ) of the positive sigmoidal thermal niche function, and calculating the sum of squares of differences between the predicted occurrence value for each temperature category $(T)$ and the actual occurrence value. This was repeated $>20000$ times to obtain the best fit (on a least sum of squares basis) between the equation describing the thermal niche and the actual occurrence of common dolphin in relation to water temperature. By introducing these best fit-derived values for $S$ and $C$ into the above formula, the resulting quantified function can be used to calculate the likelihood of occurrence for common dolphin based on water temperature at any given time and location $(T N)$. This likelihood of occurrence ranges from 0 (unsuitable water temperatures that are outside the species thermal niche) to 1 (core water temperatures at the centre of the thermal niche), with a slope between these 2 asymptotes (marginal water temperatures at the edge of the species thermal niche).

\section{Predicting species range under specific climatic conditions}

In order to predict the species range under specific climatic conditions, information on temperature $(T)$ for each grid cell in the area covered by the habitat 
model is required for a specific time period of interest. This is achieved by creating a temperature grid with the same resolution and extent as the habitat niche model output for a specific time period. The thermal niche model output is then applied to this temperature grid to produce a cell-specific thermal niche weighting value between 0 and 1 . The habitat model is then multiplied by the thermal niche weighting to estimate the likelihood of occurrence within each cell based on both the habitat niche model and the thermal niche model. Where the thermal niche weighting value is 1 , the likelihood of occurrence is defined solely by habitat preferences; with a value of 0 , it is defined solely by the temperature preferences. Between these 2 values, the likelihood of occurrence is defined by an interaction between habitat and temperature preferences, with occurrence contracting towards the core of the habitat niche as the temperature weighting value decreases (see Fig. 2). Finally, the predicted occurrence was re-scaled on a scale of 0 to 1 to create a habitat suitability index where 1 indicated the most suitable habitat within the region and zero the least suitable habitat. This was done by dividing the value in each cell by the maximum predicted likelihood of occurrence for a specific model prediction.

For common dolphin in the Northeast Atlantic, decadal predictions of summer range between 1930 and 2008 were created using SST data extracted from the HadiSST dataset. The average summer decadal SST was calculated for each $1^{\circ}$ grid cell and rescaled to a resolution of $2.5 \mathrm{~km}^{2}$. The thermal niche model was then applied to each decadal SST grid, and the habitat niche model was multiplied by each in turn, to estimate the likelihood of each grid cell falling within the species thermal and habitat niche, and therefore within the species range, for each specific decade.

\section{Model validation}

The ability of the model to predict the current static range of the species was evaluated by comparing it to the known current distribution of the species. In relation to common dolphin in the Northeast Atlantic, the distribution of common dolphins from the JNCC Cetacean Distribution Atlas (Reid et al. 2003) was used to represent an independent source of information on the current distribution of the species, as this represents the most comprehensive analysis of cetacean species distribution in this region (data available at http://jncc.defra.gov.uk/page-2713). There was a degree of overlap between the model-building data used in this study and the JNCC Atlas dataset, although the effect of this on model validation output is considered minimal. This is because, while JNCC data was also used to build the combined envelope model, this constituted only $18 \%$ of all common dolphin sightings and $<1 \%$ of all model building data. In addition, only $21.5 \%$ of total sightings contained within the Atlas dataset for UK waters were JNCC data, with $\sim 78.5 \%$ of sightings derived from 2 other sources (UK Mammal Society Cetacean Group/Sea Watch Foundation and the Sea Mammal Research Unit), which were not included in the model building data set.

These data were compared to the predicted range of common dolphin from the combined thermal and habitat niche models based on the average summer water temperatures between 2000 and 2008. Data

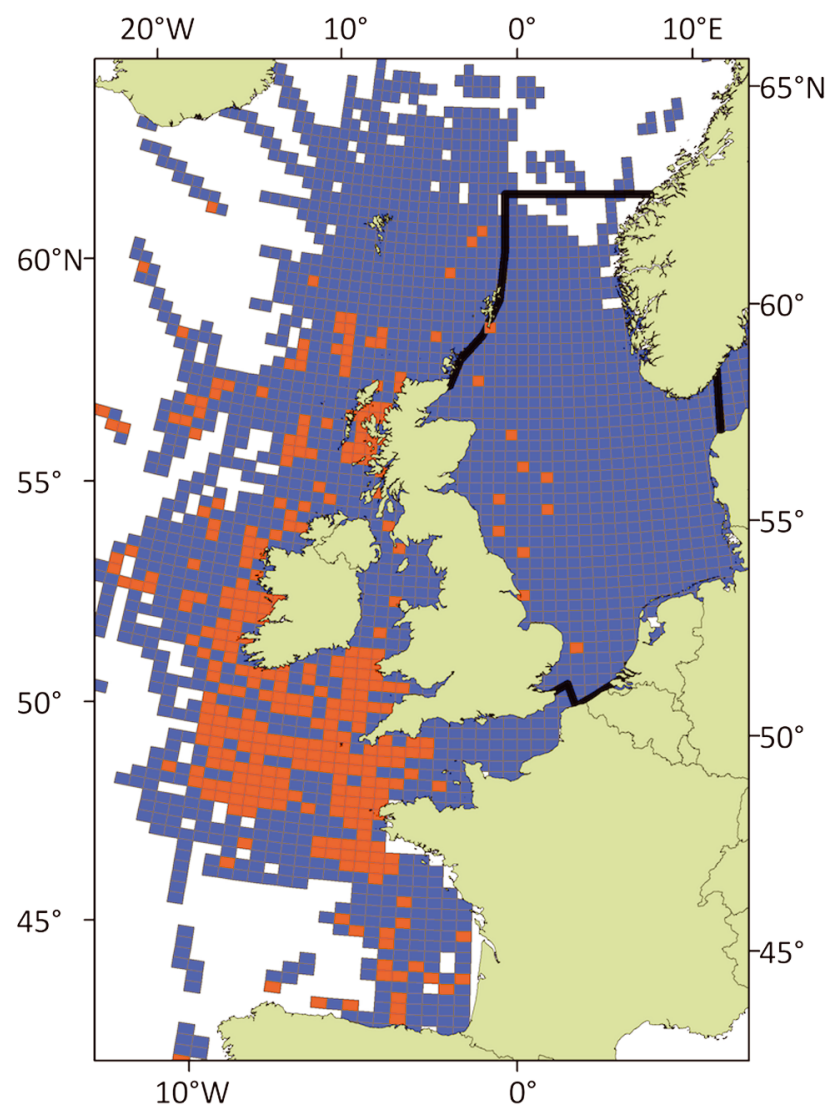

Fig. 4. ICES $1 / 4$ grid rectangles $\left(0.25^{\circ}\right.$ latitude $\times 0.5^{\circ}$ longitude) for Atlas surveyed areas (Reid et al. 2003): common dolphin Delphinus delphis was recorded as absent (blue) or as present (red). Validation of current modelled range tested the difference in mean modelled occurrence (based on 2000-2008 water temperatures) between ICES present and absent grid rectangles. Black outlined area: geographic region used to validate the models' ability to predict changes in range over time with changing water temperatures 
from both the Atlas dataset and the modelled prediction were extracted for each ICES $1 / 4$ grid rectangle $\left(0.25^{\circ}\right.$ latitude $\times 0.5^{\circ}$ longitude $)$ surveyed by the Atlas data (Fig. 4). As the modelling process in this study is primarily aimed at predicting the range of the species under different climatic conditions, and not the density of the species occurrence within the range, ICES $1 / 4$ grid rectangles where common dolphins were recorded in the Atlas dataset were classified as present, while those which had at least some survey effort in them, but where common dolphins were not recorded, were classified as absence. These were then compared to the predicted occurrence in each ICES $1 / 4$ grid cell using the predicted occurrence as an independent variable and presence or absence from the Atlas dataset as the dependent variable within a GAM with a binomial distribution and logistic link function, conducted in BRODGAR software linked to $\mathrm{R}$ 2.6.0. A significant positive relationship between the predicted occurrence and the presence of common dolphin within each ICES $1 / 4$ grid cell would indicate a validated model of the current static range of common dolphin. In addition, as the species range was the most important element of the species distribution to be validated, it was deemed more important to achieve a low number of false negatives (i.e. predicting a species is absent when it is actually present) than a low number of false positives (i.e. predicting a species as present when it is actually absent). Thus, it was deemed more appropriate for the purposes of this study to have a model that overpredicted species occurrence within the range rather than under-predicted the range itself. This is because there are likely to be additional factors that influence a species distribution within its range that are not included in this range model (potentially resulting in over-prediction in the current model).

The second validation step specifically tested the ability of the model to predict changes in the species range over time in response to changes in water temperature. Here, it is only in regions where species range is predicted to change over time that the ability of the model to predict changes in species range in response to changes in climate can be fully tested. Therefore, the spatial area with the greatest predicted change in range over time needed to be identified, and changes in occurrence of the species within this region from an independent data set need to be compared to the model's predictions. For this study, the area with the greatest predicted change between 1930 and 2008 was identified as the North Sea, based on a comparison of the model predictions for each decade (Fig. 4). This is consistent with this area representing the cool water edge of common dolphin distribution in the Northeast Atlantic (Reid et al. 2003, MacLeod et al. 2007).

Obtaining an independent data set for a time period beyond that which was used to create a model is extremely difficult for cetaceans, given that the collection of sea-based survey data did not start in earnest until the late 1970s. However, in the UK (which constitutes the eastern boundary of the North Sea), systematic stranding records are available going back as far as 1913 (e.g. Fraser 1974, Sheldrick 1989). While stranding records have a number of potential limitations, such as the influence of oceanographic features on the timing and location of a stranding, when investigated, it has been found that there is high fidelity between sighting and stranding data in relation to the distribution, composition and abundance of cetaceans for the same region (Maldini et al. 2005, Pyenson 2011). In addition, stranding data are commonly used to establish the presence of a species within a specific region, and therefore help determine a species range (e.g. MacLeod et al. 2004, Norman et al. 2004, Jefferson et al. 2009). Further, given a sufficiently comprehensive stranding reporting scheme, such as that in the UK, changes in species occurrence within the stranding record over time are likely to reflect changes in the species spatial distribution at sea (e.g. MacLeod et al. 2005, Pyenson 2011). Therefore, UK stranding data provided a suitable long-term independent data set of likely presence or absence of common dolphin within the British North Sea and enabled us to evaluate the model's predictive ability over a 76 yr period, which is substantially longer than the period of data collection for the data used to build the model.

To use these data to validate the ability of the model to predict changes in the range of common dolphin over time, we firstly calculated the average number of years per decade in which common dolphins were recorded in the British North Sea stranding record between 1930 and 2006. This provided a measure of how frequently common dolphins were present in the North Sea each decade, and limits the influence of reporting effort compared to a measure based on total stranding numbers. We then calculated the average predicted occurrence of common dolphins for all grid cells in the North Sea validation area (Fig. 4) for the same decade-long time-periods, as this provided a region-wide measure of how the species range in the North Sea is predicted to change over time. An average value could be used in this way as it is only the temperature value that is changing over time and not the underlying habitat. Therefore, a change in the av- 
erage predicted occurrence would indicate a response to changes in water temperature in this region. Specifically, an increasing value between successive decades would indicate an expansion into otherwise suitable habitat areas within the North Sea region, while a decreasing value would indicate a contraction in the species range out of such habitat areas within the North Sea region.

The predicted occurrence within the North Sea region in each decade was compared to the average number of years in which common dolphins were recorded stranded on British North Sea coasts using a Pearson correlation conducted in SPSS software (version 17.0). A positive correlation between modelled predicted occurrence and common dolphin presence in the stranding record over the same decades for the North Sea validation area would indicate that the model is successful at predicting changes in the range of common dolphin in response to changes in water temperature over time.

\section{Predicting future occurrence of common dolphin under the projected effects of climate change}

Once the predictive ability of the combined habitat niche and thermal niche model has been assessed (and assuming its predictive ability has been validated), the model can then be used to predict how the distribution of a species is likely to change under future changes in climate. For common dolphin in the Northeast Atlantic, future predicted distributions were made using projections of SST from the HadCM3 climate model (Johns et al. 2003) using the combined habitat and thermal niche model. For these predictions, we used average projected SST data for summer months following the A1b emission scenario (Nakićenović et al. 2000) for each decade between 2010 and 2069.

\section{RESULTS}

\section{Habitat niche model}

Of the 3 topographic habitat variables included in the analysis, the classification tree identified water depth as the most important variable defining common dolphin occurrence in the Northeast Atlantic, followed by standard deviation of slope (Fig. 5). The habitat niche map constructed from this classification tree (Fig. 6a) shows common dolphin occurrence to be highest over the continental shelf and shelf edge in water depths between 67.5 and $2498 \mathrm{~m}$, and where

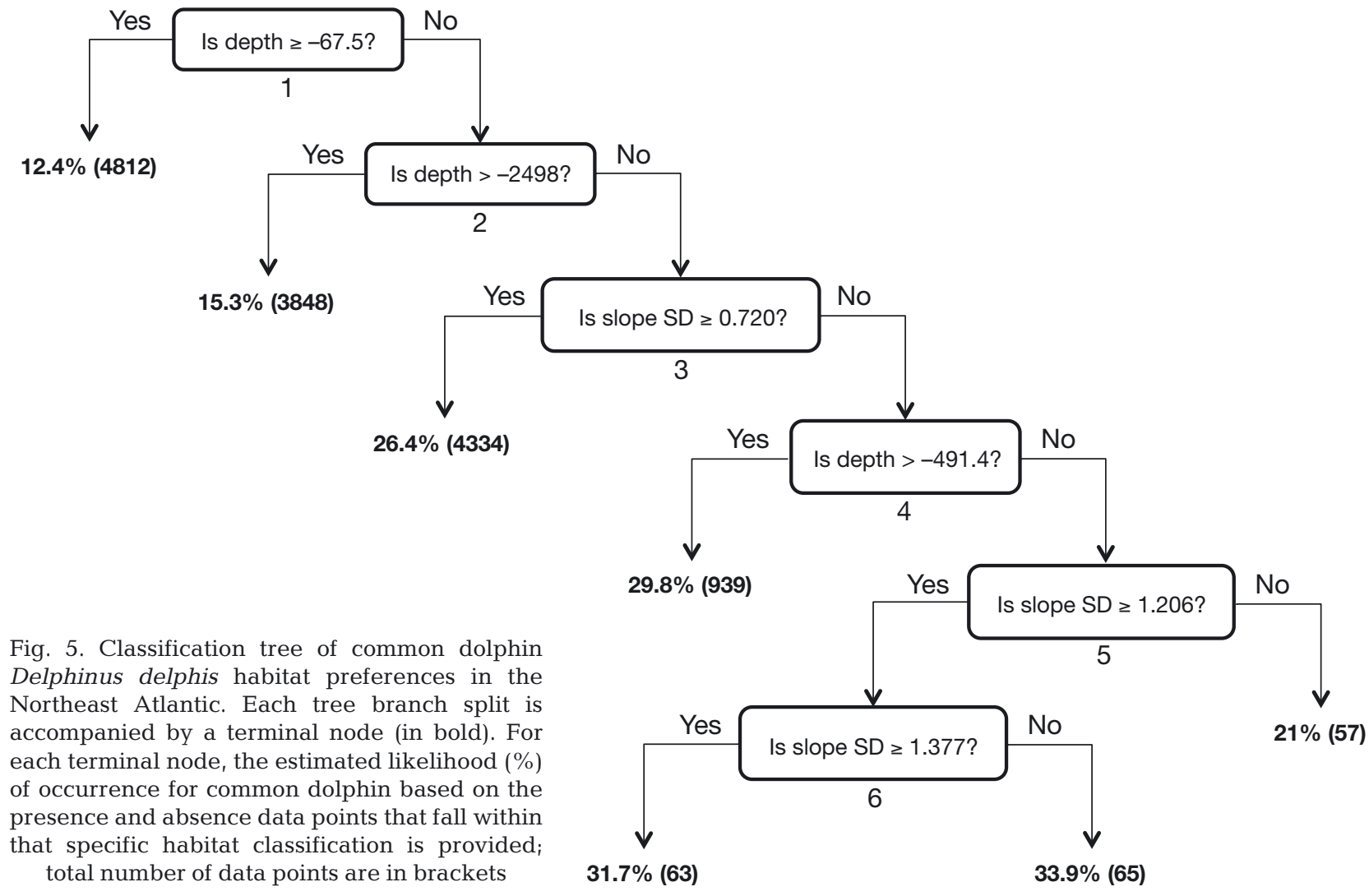


the standard deviation of slope ranges between 0.7230 and 1.377. This is consistent with previous studies of common dolphin habitat preferences in this region (e.g. MacLeod et al. 2007). The habitat model also predicts extensive occurrence of common dolphin from the north of the UK to the Norwegian Sea (Fig. 6a), an area where this species is rarely recorded in summer months (Reid et al. 2003, MacLeod et al. 2007).

\section{Thermal niche model}

The fitted thermal niche model with the lowest sum of squares had values of 0.58 and 11.48 for slope (s) and central point $(c)$ respectively. The modelled threshold between unsuitable and marginal temperature was $\sim 8^{\circ} \mathrm{C}$, while the threshold between marginal and core temperature was $\sim 14^{\circ} \mathrm{C}$ (Fig. 7). This corresponds with the known summer temperature preferences of this species around the UK and Ireland (e.g. MacLeod et al. 2007). When this thermal niche model is combined with the habitat niche model, the resulting predicted range is more in keeping with the known range of common dolphin in the Northeast Atlantic than the prediction of the habitat niche model alone (Fig. 6b).
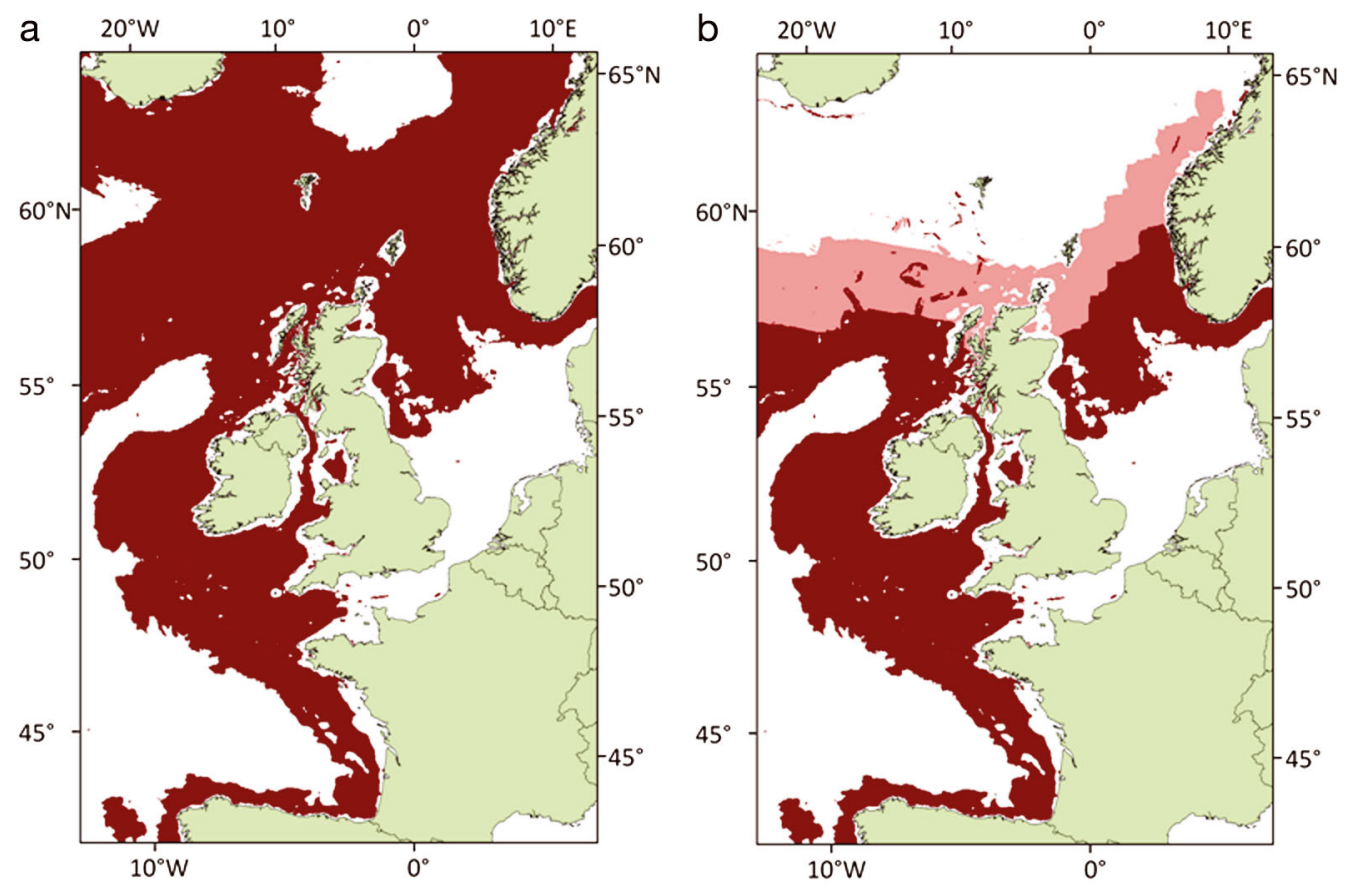

Fig. 6. Predicted occurrence of common dolphin Dolphinus delphis using (a) the habitat model alone and (b) the combined habitat and thermal niche models for 2000-2008. White shading: unsuitable habitat, with a low $(<0.25)$ predicted likelihood of occurrence; pink shading: marginal habitat with a predicted likelihood of occurrence of $0.25-0.30$; dark red shading: core habitat with a high $(>0.30)$ predicted likelihood of occurrence 


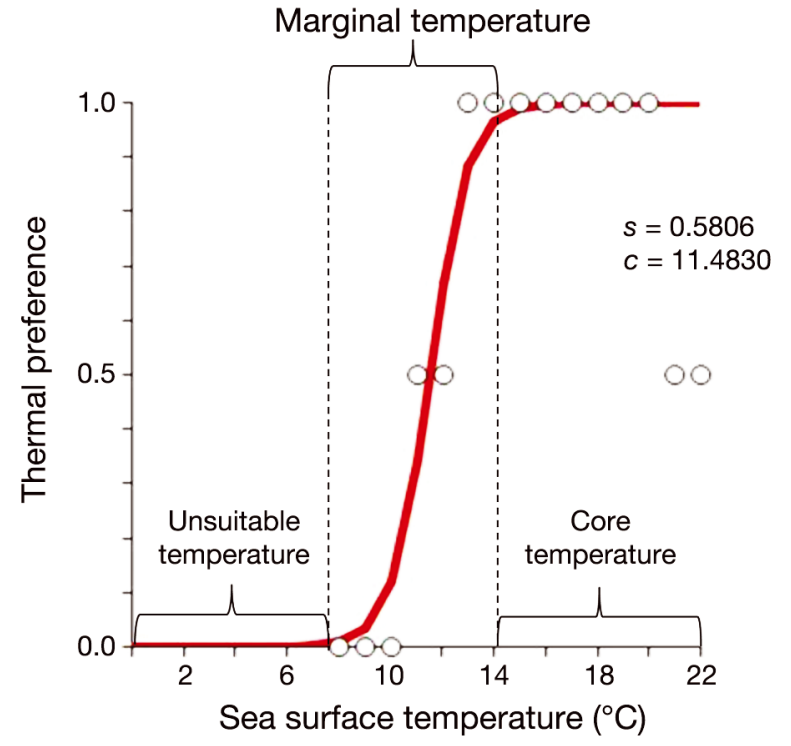

Fig. 7. The best-fitting thermal niche function (using the warm water limited group base-function) for the common dolphin Dolphinus delphis in the Northeast Atlantic, where slope $(s)=0.58$ and central point $(c)=11.48$. Circles: reclassified common dolphin occurrence in relation to water temperature, where $0=$ unsuitable temperatures, $0.5=$ marginal temperatures and $1=$ core temperatures

in relation to water temperature (while controlling for the effect of topography on spatial distribution), rather than to model the distribution of a species within its range. This means that while the model does not as accurately predict the presence of a species within its range, it accurately predicts where common dolphin is absent, and hence provides a good representation of common dolphin geographic range itself between 2000 and 2008 .

Predictions of common dolphin range in each decade from 1930-1939 to 2000-2008 show marked differences, particularly in the North Sea (Fig. 9). This predicted range was most limited in the period 1960-1969, which was the decade when the lowest average SST was recorded (Figs. 9 \& 10). In comparison, the prediction for 1940-1949 showed a more northern range extent, while the period of 2000-2008 showed the greatest range extent of all the years modelled.

In terms of validating the model's ability to predict changes in range over time in response to changes in water temperature, there was a strong and significant positive correlation between predicted common dolphin occurrence in the North Sea region as a whole and the occurrence of common dolphin strandings within the stranding record $(\mathrm{r}=0.731, \mathrm{n}=8$ decades, $\mathrm{p}=0.039$, Fig. 10). Indeed, the $\mathrm{R}^{2}$ value indicates that $53 \%$ of the variation in the strandings was matched by similar variation in predicted occurrence in the North Sea region across this time period. Overall, this presents a clear indication that the model of common dolphin occurrence constructed from sighting data collected between 1980 and 2007 accurately reflects actual changes in range in response to changes in water temperature over a longer time period. The validation process, therefore, provides some confidence in the ability of this particular model to predict the likely responses to local climate changes rather than just reflecting a static distribution in relation to current climatic conditions.
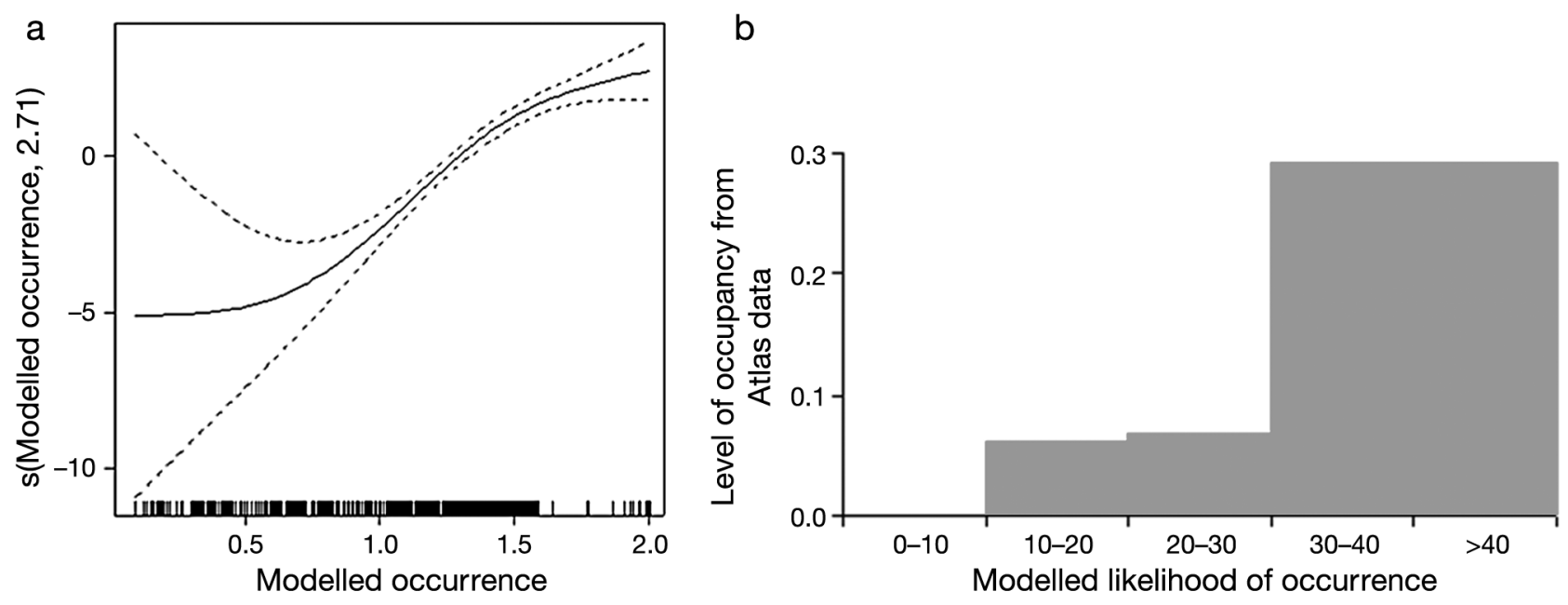

Fig. 8. (a) Generalised additive model for predicted modelled occurrence of common dolphin Dolphinus delphis ( $p>0.001$, deviance explained $=13.6 \%, \mathrm{n}=2267$ ); (b) Plot of modelled likelihood of occurrence against the actual occupancy derived from the Atlas data (Reid et al. 2003) for ICES $1 / 4$ grid cells 

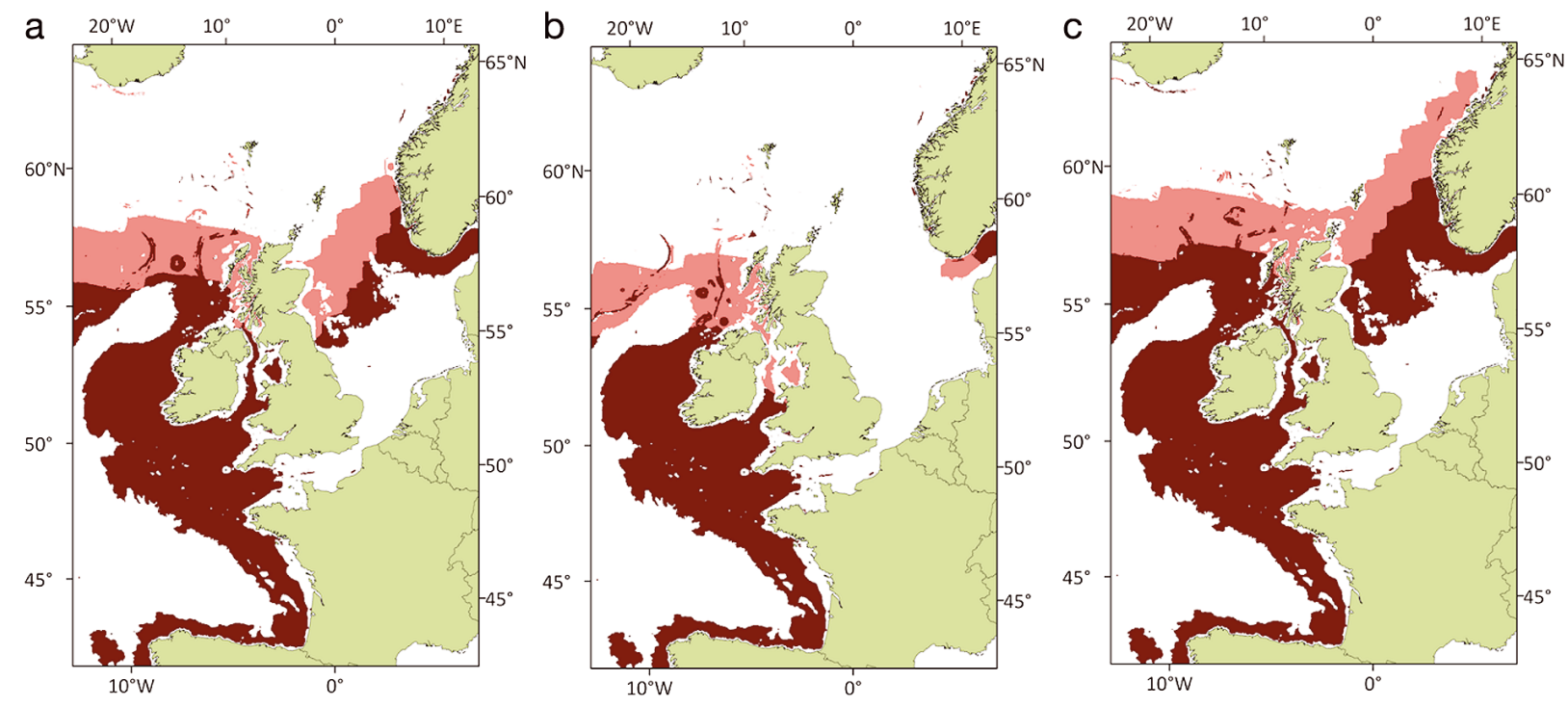

Fig. 9. Predicted range of common dolphin Dolphinus delphis from the combined thermal and habitat model for (a) 1940-1949, (b) 1960-1969 and (c) 2000-2008. Habitats: white = unsuitable, pink = marginal, dark red = core. See Fig. 6 for details of colors

\section{Future predicted range of common dolphin in the NE Atlantic}

Based on the above validated model and projected SST data for the periods 2020-2029, 2040-2049 and 2060-2069, the range of common dolphin is predicted to expand progressively northwards as water temperatures increase over time (Fig. 11). In particular, the model predicts that the area of otherwise suitable habitat to the north of the UK, which is currently unoccupied by common dolphins, is likely to become occupied as temperatures increase and, as a result, start to fall within the species thermal niche.

\section{DISCUSSION}

Based on the framework provided by MacLeod (2009), we have developed a relatively simple and widely applicable bioclimatic envelope modelling approach that captures the interaction between the habitat and thermal niche occupied by a cetacean species, and which can be used to predict how a species geographic range is likely to change under different climatic conditions. In particular, our analysis supports the hypothesis that water temperature is a limiting factor in the geographic range of certain cetacean species (MacLeod 2009, Salvadeo et al. 2010, Kaschner et al. 2011). Consequently, with climate change expected to have significant impacts on the world oceans in the short to medium term (IPCC 2007), we expect the geographic range of certain cetacean species to shift alongside future changes in temperature.

Robust projections of future species ranges require that predictive ability of models are suitably evaluated, preferably using independent datasets (Araújo et al. 2005). Typically, bioclimatic model evaluation focuses on the ability of a model to reflect the current distribution of a species. However, confidence in predicting the response of species distributions to novel climates is considerably enhanced where it is possible to evaluate the predictive accuracy of the model against historic changes in a species range alongside documented changes in climatic variables, such as temperature (Araújo et al. 2005, Martínez-Meyer 2005, Willis et al. 2009). Thus, model validation beyond the time period of data used for its construction is an essential step if predictions from the model are to be used for conservation and management purposes. Here, not only were we able to validate the models' ability to predict current range limits but, importantly, the availability of long-term stranding records in the UK also enabled evaluation of the models' ability to predict how these range limits have altered as the environment changed over a $76 \mathrm{yr}$ period (in comparison to the $28 \mathrm{yr}$ of data collected to construct the model). Specifically, water temperatures in the North Sea have varied across 3 distinct phases since 1930, with 2 periods of higher temperatures (1930-1949 and 1980-present) separated by a period of low temperatures (1950-1979). By using the long-term strandings dataset, we could investigate the extent of agreement between observed and pre- 

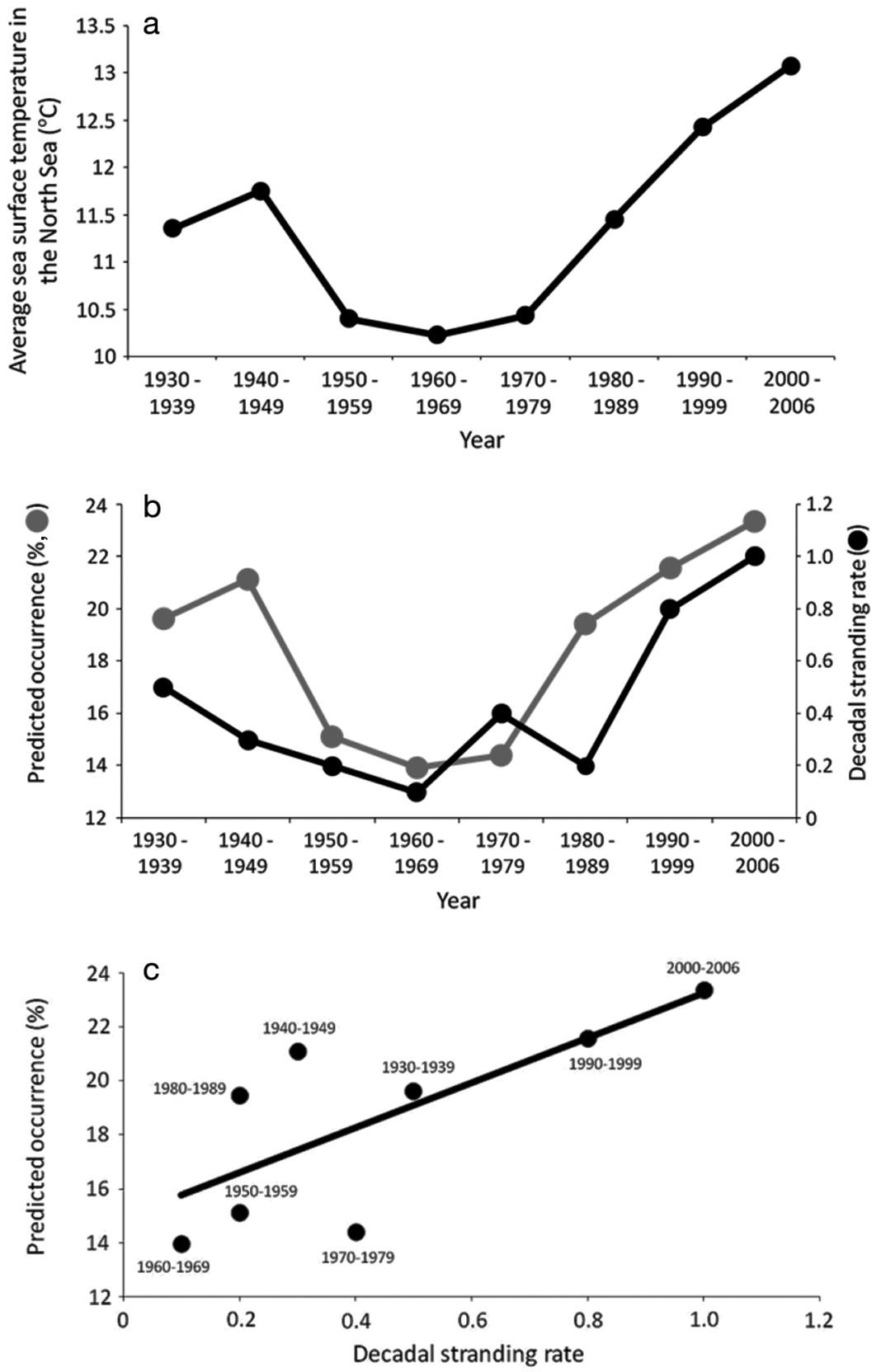

Fig. 10. (a) Average summer sea surface temperature (SST) for the North Sea across the years modelled for validation; (b) trend in modelled occurrence of common dolphin Delphinus delphis on the North Sea as a whole (๑) and historic stranding data (๑) from 1930-2006; (c) correlation between modelled occurrence in the North Sea as a whole and average decadal stranding occurrence $\left(\mathrm{R}^{2}=0.53, \mathrm{p}=0.039\right)$

dicted range changes over this period of large-scale variations in temperature.

While the increase in the number of common dolphins recorded stranded on British North Sea coasts in the 1990s and 2000s could, in part, be due to an increase in reporting effort since 1990, we argue that this would have had little effect on the overall rela- tionship between decadal changes in modelled occurrence in the North Sea as a whole and the average number of years in any given decade during which common dolphins were recorded stranded. Firstly, there is a good fit between the model data and stranding rates across all 3 of the temperature phases described above and not just during the last 2 decades when stranding recording effort is known to have increased. In particular, the model successfully predicted the decline in strandings of common dolphin between the 1930s and 1950s as temperatures in this region declined (see Fig. 10b), as well as the increase in recent years when temperatures have increased again, and this correlation cannot be a result of any bias caused by an increase in stranding recording efforts in the last 2 decades. Secondly, the occurrence of common dolphin in the North Sea was measured by common dolphin presence per year in the stranding record as opposed to the total number of common dolphin strandings, thereby reducing the impact of monitoring effort on the observed decadal scale variation in strandings rate. Therefore, the relationship between predicted range change and changes in the stranding data between 1930 and 2006 is likely to represent a true ability to detect change in species range over time rather than as a result of a bias in the stranding data due to enhanced recording effort since the 1990s. In addition, this suggests that the changes in the occurrence of common dolphin in the British North Sea stranding record do, indeed, reflect changes in species range over time.

To date, there has been little research addressing the conservation implications of changes in the ranges of cetacean species over time. Yet, until we have a greater understanding of how cetacean species ranges may shift in response to climate change, developing specific mitigation strategies to counter potentially negative impacts is extremely difficult (UNEP/CMS 2006, IWC 2009). The modelling approach presented here rep- 

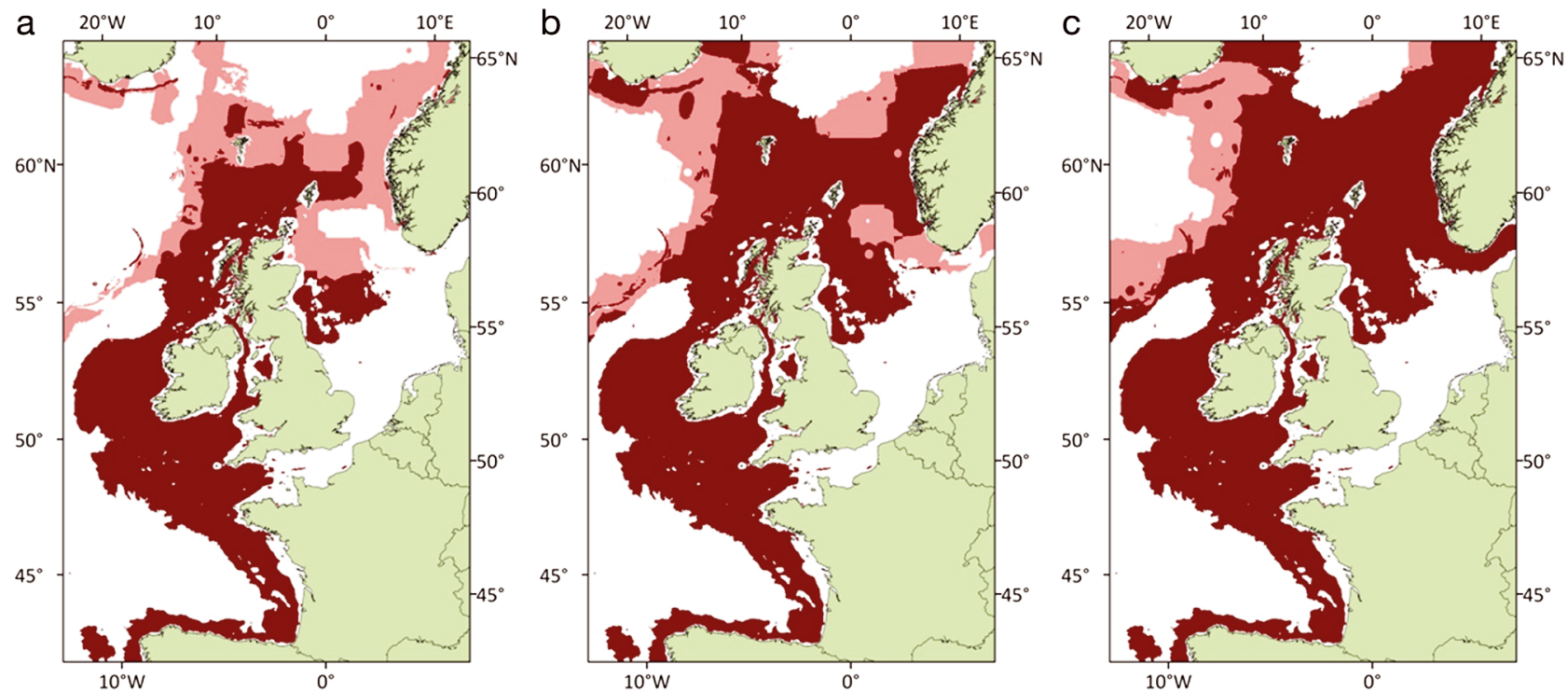

Fig. 11. Predicted future range of common dolphin Dolphinus delphis based on projected A1b Scenario (Naćenović et al. 2009) sea surface temperature data for years (a) 2020-2029,(b) 2040-2049 and (c) 2060-2069. Habitats: white = unsuitable, pink = marginal, dark red = core. See Fig. 6 for details of colors

resents a first step towards achieving the required level of understanding of this potential effect of climate change on cetaceans. For example, by applying this modelling approach to the common dolphin in the Northeast Atlantic, we can predict that, if temperature change follows the A1b medium emission scenario (Naćenović et al. 2009), the geographic range of common dolphin is likely to progressively expand further northwards between the 2010s and the 2060s, from northern UK shelf waters, to Faroese waters and eventually the Norwegian Sea (Fig. 9). In addition, this demonstrates that while assessments of climate change impacts often concentrate on the negative implications for cetacean species (Learmonth et al. 2006, Simmonds \& Isaac 2007), it is also important to recognise that not all species will necessarily be negatively affected by climate change. For example, the common dolphin, a warm water limited species that occupies both oceanic and shelf waters, is predicted to benefit from an expanded distribution in the Northeast Atlantic.

While the model presented here predicts a northward range expansion of common dolphin in the Northeast Atlantic under climate change, evidence potentially exists that the actual outcome may, instead, be a northwards range shift. Specifically, while the common dolphin in this region was classified as a WWL species, the re-classified values of common dolphin distribution in relation to water temperatures showed potential evidence of a reduction in relative common dolphin occurrence in waters $>21^{\circ} \mathrm{C}$ (see Fig. 6). This could indicate that the common dolphin in the Northeast Atlantic is actually a CWWL species, and does not occur in the warmest waters. This has also been suggested for common dolphins in the western Atlantic (Jefferson et al. 2009). However, further investigation of this issue was not possible in this study as the range of water temperatures sampled was not sufficient to determine the most appropriate form for the thermal niche function in the warmest water temperatures found in the Northeast Atlantic. Therefore, for this study, the common dolphin was classified as a WWL species based on the best currently available information (Evans 1994, Rice 1998, Kaschner 2004).

However, the possibility that common dolphins in the Northeast Atlantic area may not occur in the warmest waters should be borne in mind when interpreting the results of these models. Specifically, the predicted future ranges are potentially more accurate for the northern portion of the study area, where the range is predicted to expand, and may require modification at the southern end of this study area. In addition, this highlights that, while the modelling process developed here may be applicable to a wide variety of cetaceans, and indeed other marine species, the specific model developed for the common dolphin should not be extrapolated to other regions of the world without repeating the model validation steps specified above to ensure it is valid to do so.

One potential limitation of the proposed modelling approach is that it does not account for how biotic 
interactions may change with changing environmental conditions, which could alter the potential for species to inhabit an otherwise suitable habitat (Davis et al. 1998, Pearson \& Dawson 2003). Except for barriers related to seabed topography, we have assumed universal dispersal capabilities, and that the tolerance range of species will remain the same over time (i.e. niche conservatism; see Pearson \& Dawson 2003 for a detailed review of these limitations).

Bearing in mind these possible limitations, the approach presented here nevertheless provides a first step towards being able to model the impacts of climate change on cetacean species ranges, and the validation process demonstrates that even with the relatively simplistic approach developed here, a large amount of the variation in species range resulting from climate change can be captured by such a model. Further development of this modelling approach could overcome the above-mentioned limitations by incorporating into the modelling process the functional mechanisms that drive the link between water temperature and cetacean occurrence. This, in turn, may improve accuracy of simulated distributions under scenarios of climate change (Guisan \& Zimmermann 2000, Hijmans \& Graham 2006, Kearney \& Porter 2009). At present, the functional mechanisms that link cetacean distribution to water temperature are unclear. Three hypotheses have, so far, been proposed: (1) There is a direct relationship between a species' thermal limits and water temperature, driven by the physiology of the species (MacLeod 2009); (2) There is an indirect relationship, as defined by the effects of water temperature on prey distribution (Learmonth et al. 2006); (3) The relationship is defined by the effect of temperature on the outcome of competitive interactions (MacLeod et al. 2007). It is not known which, if any, of these hypotheses are correct, or indeed whether they are mutually exclusive. Until these mechanisms are better understood, incorporating functional mechanisms into the ecological modelling approach present here will remain difficult and at best speculative.

In general, bioclimatic envelope models are considered a useful and appropriate starting point for estimating climate change impacts on species ranges and sites of conservation importance (Dockerty et al. 2003, Pearson \& Dawson 2003, MartínezMeyer 2005). The ability to predict the response of cetacean ranges to future water temperature changes is, therefore, important for progressing beyond static and typically reactive conservation management approaches towards more dynamic and adaptive ones, which can better account for changes in species ranges as a result of climate change. In this way, scenarios of changes in species ranges can be an important component to exploring how individual species, or overall biodiversity, could be redistributed at specific points in the future in relation to management boundaries or areas of high vulnerability (e.g. Téllez-Valdés \& Dávila-Aranda 2003, Hannah et al. 2007, Kaschner et al. 2011). For example, we predict that by the 2020s common dolphin range will expand beyond the boundaries currently set in place under the Agreement on the Conservation of Small Cetaceans of the Baltic and the North Seas (ASCOBANS). As such, mitigation measures to prevent bycatch, the largest threat facing common dolphins in this region (Reeves et al. 2003, DEFRA 2009), may need to be introduced outside the current 'Agreement' and 'Extended Agreement' ASCOBANS boundaries as common dolphin range expands. Therefore, even given the relatively simplistic approach applied to our case study, the validation procedure suggests that the combined habitat niche and thermal niche model has an ability to make an initial quantitative assessment of where and when individual species ranges, such as that of the common dolphin, will shift with changes in climate, and therefore provide important information for conservation and management purposes.

Acknowledgements. This study was funded by the University of Aberdeen through a Systems Biology studentship. UK strandings data (1990-2007) was provided by the UK Cetacean Strandings Investigation Programme, while UK strandings data pre-1990 were provided by the Natural History Museum, London. The authors also acknowledge the Irish Whale and Dolphin Group, the Biscay Dolphin Research Programme and the contribution of the volunteer surveyors for their efforts in data collection for these organisations. Additional sightings were provided by the Joint Nature Conservation Committee (JNCC). The JNCC is the statutory adviser to the UK Government and devolved administrations on UK and international nature conservation. Its work contributes to maintaining and enriching biological diversity, conserving geological features and sustaining natural systems. JNCC delivers the UK and international responsibilities of the Council for Nature Conservation and the Countryside (CNCC), the Countryside Council for Wales (CCW), Natural England, and Scottish Natural Heritage (SNH). We also gratefully acknowledge the use of sea surface temperature data from the Met Office Hadley Centre (www.metoffice.gov.uk/hadobs) and the modeling groups, the Program for Climate Model Diagnosis and Intercomparison (PCMDI) and the WCRP's Working Group on Coupled Modelling (WGCM) for their roles in making available the WCRP CMIP3 multi-model dataset. Support of this dataset is provided by the Office of Science, US Department of Energy. 


\section{LITERATURE CITED}

Araújo MB, Pearson RG, Thuiller W, Erhard M (2005) Validation of species-climate models under climate change. Global Chang Biol 11:1504-1513

Davis AJ, Jenkinson LS, Lawron JH, Shorrocks B, Wood S (1998) Making mistakes when predicting shifts in species range in response to global warming. Nature 391: 783-786

$>$ De'ath G, Fabricius KE (2000) Classification and regression trees: a powerful yet simple technique for ecological data analysis. Ecology 81:3178-3192

DEFRA (2009) UK small cetacean bycatch response strategy. Department of Environment, Food and Rural Affairs, London

> Dockerty T, Lovett A, Watkinson A (2003) Climate change and nature reserves: examining the potential impacts, with examples from Great Britain. Glob Environ Change 13:125-135

Evans WE (1994) Common dolphin, white-bellied porpoise Delphinus delphis Linnaeus, 1758. In: Ridgway SH, Harrison $\mathrm{R}$ (eds) Handbook of marine mammals, Vol 5. Academic Press, San Diego, CA

Fraser FC (1974) Report on Cetacea stranded on the British coast from 1948 and 1947. No. 13. British Museum, Natural History, London

Guisan A, Zimmermann NE (2000) Predictive habitat distribution models in ecology. Ecol Model 135:147-186

Hannah L, Midgley GF, Millar D (2002) Climate changeintegrated conservation strategies. Glob Ecol Biogeogr 11:485-495

Hannah L, Midgley G, Andelman S, Araujo M and others (2007) Protected area needs in a changing climate. Front Ecol Environ 5:131-138

> Hijmans R, Graham CH (2006) The ability of climate envelope models to predict the effect of climate change on species distributions. Glob Change Biol 12: 2272-2281

Hutchinson GE (1957) Concluding remarks. Cold Spring Harbour Symposia on Quantitative Biology 22:415-427

IPCC (Intergovernmental Panel on Climate Change) (2007) Summary for policymakers. In: Solomon S, Qin D, Manning $M$, Chen $Z$ and others (eds) Climate change 2007: the physical science basis. IPCC, Cambridge University Press, Cambridge, p 18

IWC (2009) Draft report of the workshop on cetaceans and climate change. Scientific Committee of the International Whaling Commission (IWC), SC/61/Rep 4, Siena

Jefferson TA, Fertl D, Bolaños-Jiménenz J, Zerbini AN (2009) Distribution of common dolphins (Delphinus spp.) in the western Atlantic Ocean: a critical re-examination. Mar Biol 156:1109-1124

Johns TC, Gregory JM, Ingram WJ, Johnson CE and others (2003) Anthropogenic climate change for 1860 to 2100 simulated with the HadCM3 model under updated emissions scenarios. Clim Dyn 20:583-612

Kaschner K (2004) Modelling and mapping of resource overlap between marine mammals and fisheries on a global scale. PhD thesis, University of British Columbia, Vancouver

> Kaschner K, Tittensor DP, Ready J, Gerrodette T, Worm B (2011) Current and future patterns of global marine mammal biodiversity. PLoS ONE 6:e19653

Kearney M (2006) Habitat, environment and niche: What are we modelling? Oikos 115:186-191
Kearney M, Porter W (2009) Mechanistic niche modelling: combining physiological and spatial data to predict species ranges. Ecol Lett 12:334-350

Kiszka J, Macleod K, Van Canneyt O, Walker D, Ridoux V (2007) Distribution, encounter rates, and habitat characteristics of toothed cetaceans in the Bay of Biscay and adjacent waters from platform-of-opportunity data. ICES J Mar Sci 64:1033-1043

Learmonth JA, MacLeod CD, Santos MB, Pierce GJ, Crick HQP, Robinson RA (2006) Potential effects of climate change on marine mammals. Oceanogr Mar Biol Annu Rev 44:431-464

Leeney RH, Amies R, Broderick AC, Witt MJ, Loveridge J, Doyle J, Godley BJ (2008) Spatio-temporal analysis of cetacean strandings and bycatch in a UK fisheries hotspot. Biodivers Conserv 17:2323-2338

> Levinsky I, Skov F, Svenning JC, Rahbek C (2007) Potential impacts of climate change on the distributions and diversity patterns of European mammals. Biodivers Conserv 16:3803-3816

MacLeod CD (2009) Global climate change, range changes and potential implications for the conservation of marine cetaceans: a review and synthesis. Endang Species Res 7:125-136

MacLeod CD, Pierce GJ, Santos MB (2004) Geographic and temporal variations in strandings of beaked whales (Ziphiidae) on the coasts of the UK and Republic of Ireland from 1800-2002. J Cetacean Res Manag 6:1-8

MacLeod CD, Bannon SM, Pierce GJ, Schweder C, Learmonth JA, Herman JS, Reid RJ (2005) Climate change and the cetacean community of north-west Scotland. Biol Conserv 124:477-483

> MacLeod CD, Weir CR, Pierpoint C, Harland EJ (2007) The habitat preferences of marine mammals west of Scotland (UK). J Mar Biol Assoc UK 87:157-164

Maldini D, Mazzuca L, Atkinson S (2005) Odontocete stranding patterns in the main Hawaiian Islands (1937-2002): How do they compare with live animal surveys? Pac Sci 59:55-67

Martínez-Meyer E (2005) Climate change and biodiversity: some considerations in forecasting shifts in species' potential distributions. Biodiv Inform 2:42-55

Norman SA, Bowlby CE, Brancato MS, Calambokidis J and others (2004) Cetacean strandings in Oregon and Washington between 1930 and 2002. J Cetacean Res Manag 6:87-99

Nakićenović N, Alcamo J, Davis G, de Vries B and others (2000) Special report on emissions scenarios. Intergovernmental Panel on Climate Change (IPCC), Cambridge University Press, Cambridge

Parmesan C, Yohe G (2003) A globally coherent fingerprint of climate change impacts across natural systems. Nature 421:37-42

Pearson RG, Dawson TP (2003) Predicting the impacts of climate change on the distribution of species: Are bioclimatic envelope models useful? Glob Ecol Biogeogr 12: 361-371

Peters RL, Darling JDS (1985) The greenhouse effect and nature reserves. Bioscience 35:707-717

Pyenson ND (2011) The high fidelity of the cetacean stranding record: insights into measuring diversity by integrating taphonomy and macroecology. Proc R Soc Lond B Biol Sci 278:3608-3616

Pyke CR, Andelman SJ, Midgley G (2005) Identifying priority areas for bioclimatic representation under climate 
change: a case study for Proteaceae in the Cape Floristic Region, South Africa. Biol Conserv 125:1-9

Redfern JV, Ferguson MC, Becker EA, Hyrenbach KD and others (2006) Techniques for cetacean-habitat modelling. Mar Ecol Prog Ser 310:271-295

Reeves RR, Smith BD, Crespo EA, Notarbartolo di Sciara G (eds) (2003) Dolphins, whales and porpoises: 2002-2010 conservation action plan for the world's cetaceans. IUCN/SSC Cetacean Specialist Group, IUCN, Gland and Cambridge

Reid JB, Evans PGH, Northridge SP (2003) Atlas of cetacean distribution in north-west European waters. Joint Nature Conservation Committee, Peterborough

Rice DW (1998) Marine mammals of the world: systematics and distribution. Spec Publ 4, Society of Marine Mammalogy, Beaufort, NC

Robinson RA, Humprey QPC, Learmonth JA, Maclean IMD and others (2009) Travelling through a warming world: climate change and migratory species. Endang Species Res 7:87-99

Salvadeo CJ, Lluch-Belda D, Gómez-Gallardo A, UrbánRamírez J, MacLeod CD (2010) Climate change and a poleward shift in the distribution of the Pacific whitesided dolphin in the northeastern Pacific. Endang Species Res 11:13-19

Sheldrick MC (1989) Stranded whale records for the entire British coastline, 1967-1966. Invest Cetacea 22:298-329

Simmonds MP, Isaac SJ (2007) The impacts of climate change on marine mammals: early signs of significant problems. Oryx 41:19-26
Svenning JC, Kerr J, Rahbek C (2009) Predicting future shifts in species diversity. Ecography 32:3-4

Téllez-Valdés O, Dávila-Aranda P (2003) Protected areas and climate change: a case study of the cacti in the Tehuacán-Cuicatlán biosphere reserve, México. Conserv Biol 17:846-853

- Thomas CD (2010) Climate, climate change and range boundaries. Divers Distrib 16:488-495

Thomas CD, Cameron A, Green RE, Bakkenes M, and others (2004) Extinction risk from climate change. Nature 427:145-148

UNEP/CMS (2006) Migratory species and climate change: impacts of a changing environment on wild animals. United Nations Environment Programme (UNEP)/Secretariat of the Convention on the Conservation of Migratory Species of Wild Animals (CMS), Bonn

- Walther GR, Post E, Convey P, Menzel A and others (2002) Ecological responses to recent climate change. Nature 416:389-395

> Weir CA, Pollock C, Cronin C, Taylor S (2001) Cetaceans of the Atlantic Frontier, north and west of Scotland. Cont Shelf Res 21:1047-1071

- Weir CA, MacLeod CD, Calderan SV (2009) Fine-scale habitat selection by white-beaked and common dolphins in the Minch (Scotland, UK): evidence for interspecific competition or coexistence? J Mar Biol Assoc UK 89:951-960

> Willis SG, Thomas CD, Hill JK, Collingham YC, Telfer MG, Fox R, Huntley B (2009) Dynamic distribution modelling: predicting the present from the past. Ecography 32:5-12 
Appendix 1. Temperature response curves and associated algorithms that represent the qualitative categories proposed by MacLeod (2009). Thermal niche function calculators to derive the slope and central point for each of these curves are available at www.GISinEcology.com/useful_tools.htm

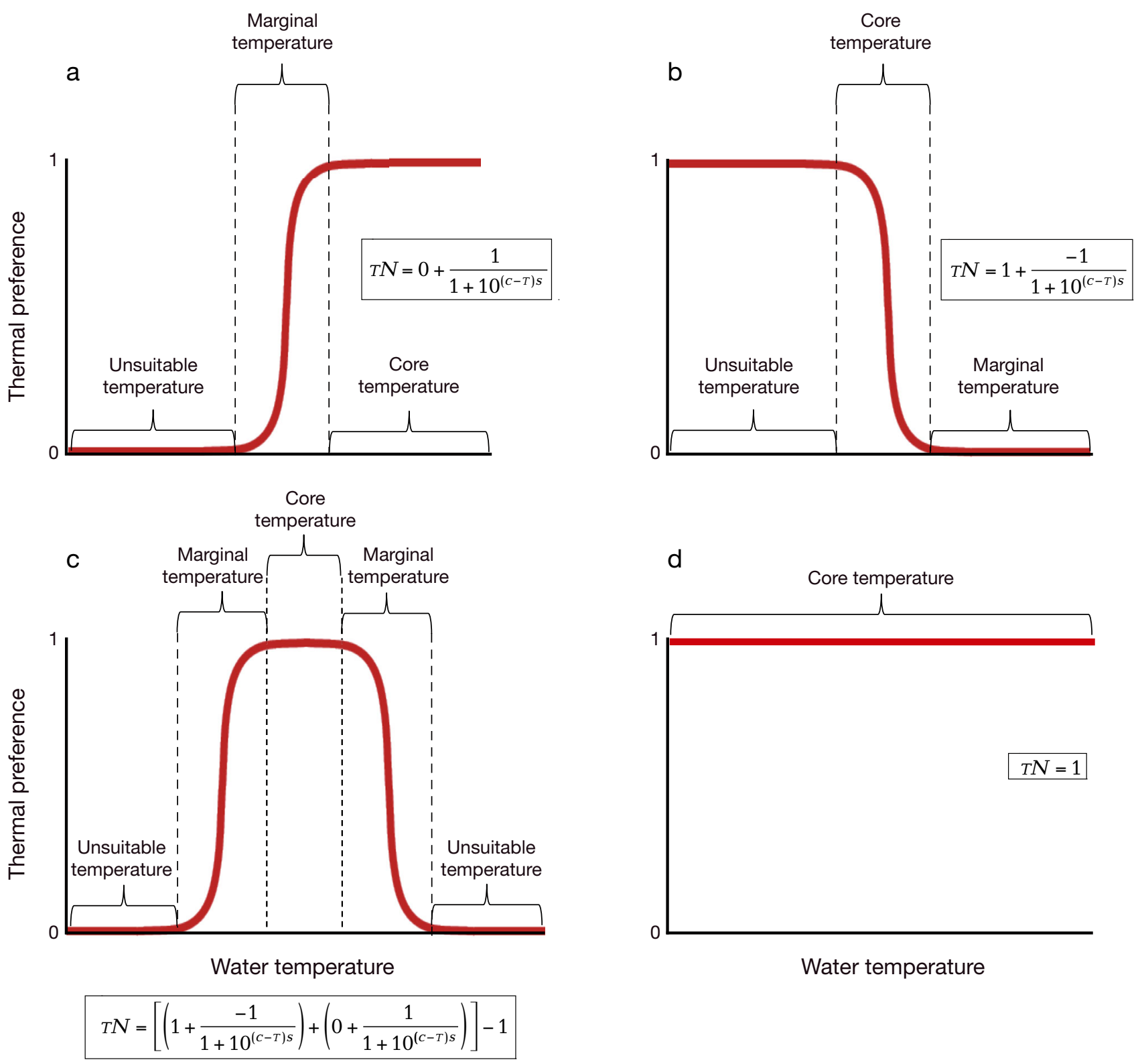

Fig. A1. Species: (a) warm water limited (WWL), (b) cool water limited (CWL), (c) cool and warm water limited (CWWL) and (d) cosmopolitan

Editorial responsibility: Kristin Laidre, Seattle, Washington, USA
Submitted: January 16, 2011; Accepted: August 16, 2011

Proofs received from author(s): November 21, 2011 